\title{
Verbal Guidance and the Efficacy of Forward Guidance
}

\author{
Daniel T. Thornton, Vice President and Economic Adviser
}

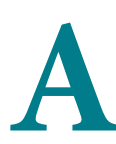

s part of its so-called unconventional monetary policy toolkit, the Federal Open Market Committee (FOMC) has engaged in forward guidanceattempting to reduce longer-term interest rates by committing to keep its short-term policy rate low for a long period into the future. The FOMC has used verbal guidance in an attempt to increase the efficacy of its forward guidance policy. For example, on August 9, 2011, the FOMC announced that "economic conditions... are likely to warrant exceptionally low levels of the funds rate at least through mid-2013." On January 25, 2012, the FOMC further strengthened its forward guidance by amending an otherwise identical statement to read "at least through late 2014," and on September 13, 2012, it extended the period to "at least through mid-2015." This essay investigates the impact of verbal guidance on the efficacy of forward guidance. ${ }^{1}$

\section{The behavior of term OIS rates following the three instances of FOMC verbal guidance provides no support for the efficacy of the FOMC's forward guidance monetary policy.}

Recently Michael Wood suggested that the first two verbal guidance statements were the "cleanest" test of forward guidance policy because (i) they "include very precise specifications of the future funds rate path quite far into the future" and (ii) the statements "did not also contain important policy changes of any other sort." 2 The August 2011 announcement made it clear that the funds rate would remain at essentially zero for at least a year from the statement date. The January 2012 statement made it clear that the funds rate would be essentially zero for about a year and a half beyond the previously announced date. The first announcement should have reduced rates only if the FOMC's announcement extended the period of a zero funds rate beyond what the market already expected. For example, if the market expected the funds rate to remain at zero for the next year, the announcement should have had no effect on rates because it would have provided no new information. Hence, it is possible that the first announcement would have had no effect on interest rates of any term to maturity. However, the second announcement should have had a significant effect on rates because it extended the zero funds rate period well beyond what the FOMC had announced six months earlier.

The effectiveness of verbal guidance on the efficacy of forward guidance is investigated by looking at the effect of these two announcements on the yield curve of rates on overnight indexed swaps (OIS) contracts. OISs are essentially a forecast of the average overnight federal funds rate over the term of the OIS contract. The first chart shows the yield curve of OIS contracts with maturities from 3 to 240 months on the day before, the day of, and 30 days after the FOMC's August 9, 2011, verbal guidance. As the chart shows, the yield curve was essentially flat (near zero) for maturities up to 1 year the day before the announcement, suggesting that just before the announcement the market anticipated that the funds rate would be essentially zero for the next year-that is, until mid-2012. The announcement should have increased the market expectation that the funds rate would be essentially zero for the next two years. Hence, the 2-year OIS rate should have declined to essentially zero the day after the announcement, but it did not. Instead, the yield curve shifted down by roughly the same amount for all maturities out to 20 years. Indeed, it shifted down the most for the 20 -year OIS rate, which declined by 13 basis points. The yield curve shifted further down during the 30 days following the announcement; the amount of the decline generally increased with the term to maturity. This is exactly the opposite of what would have occurred if the decline in the yield curve were a consequence of enhanced forward guidance. If the behavior of the yield curve were a consequence of enhanced forward guidance, the yield curve should have flattened out for maturities up to about 2 years and shifted down less as the term to maturity lengthened.

The second chart shows the OIS yield curve the day before, the day of, and 30 days after the January 25, 2012, announcement. The yield is zero for maturities of 1 year 
or less despite the FOMC's August 9, 2011, announcement that the funds rate would be essentially zero for the next year and a half. Moreover, the rate on the 2-year OIS contract is essentially the same as it was the day before the August 2011 announcement-56 basis points compared with 54 basis points on August 8, 2011. Perhaps even more surprising is that the FOMC's January 25, 2012, verbal guidance had virtually no effect on OIS rates with maturities of 3 years or less despite the announcement's suggestion that the funds rate would be essentially zero for about the next three years. The effect was the largest for maturities from 4 to 8 years. Also, unlike the response to the August 2011 announcement, the yield curve shifted down relatively little during the 30 days following the announcement. In this case, however, the largest declines occurred in the range of maturities from 5 to 10 years.

The behavior of the OIS rate immediately after the September 13, 2012, announcement offers little support for the efficacy of the FOMC's forward guidance policy. OIS rates across the term structure declined slightly the day after the announcement but increased above the September 12, 2012, level on September 14, with the amount of the increase generally rising with the term to maturity.

In summary, the behavior of term OIS rates following the three instances of FOMC verbal guidance provides no support for the efficacy of the FOMC's forward guidance monetary policy. While all of the OIS rates generally declined immediately following the first two announcements, the response of 2- and 3-year OIS rates was much smaller than the response of longer-term maturitiesexactly the opposite of the effect predicted by forward guidance. Moreover, the response of OIS rates along the yield curve cannot be explained by simply suggesting that the market was not 100 percent certain the FOMC would keep the funds rate at zero for that long. If that were the case, OIS rates would have still moved in a manner consistent with forward guidance monetary policy; the magnitude of the response would have just been smaller.

\section{Notes}

${ }^{1}$ For a proposal to improve the credibility of forward guidance, see Krippner, Leo and Thornton, Daniel T. "A Proposal for Improving Forward Guidance." Federal Reserve Bank of St. Louis Economic Synopses, 2012, No. 27, September 28, 2012.
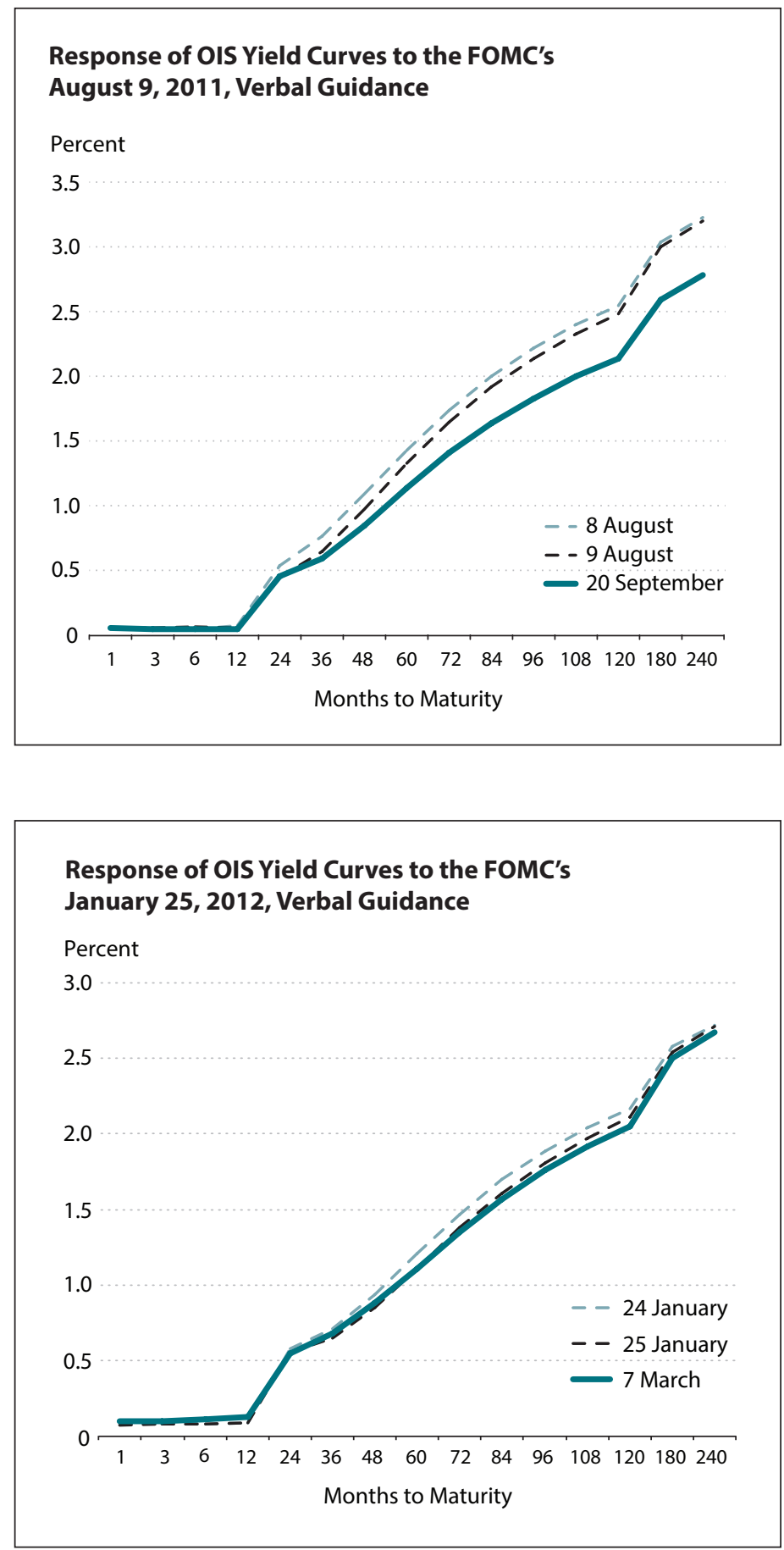

2 Woodford, Michael. "Methods of Policy Accommodation at the Interest Rate Lower Bound." Presented at a symposium sponsored by the Federal Reserve Bank of Kansas City, “The Changing Policy Landscape," Jackson Hole, Wyoming, August 31, 2012; http://kansascityfed.org/publicat/sympos/2012/mw.pdf. 